\title{
A circular monopole patch antenna loaded with inverted L-shaped stub for GPS application
}

\author{
Sowmya G. A. ${ }^{1}$, Akshtha Kamath², Anala Keshava ${ }^{3}$, Om Prakash Kumar ${ }^{4}$, \\ Shweta Vincent ${ }^{5}$, Tanweer $\mathbf{A l i}^{6}$ \\ 1,2,3,4,6 Deptartment of Electronics \& Communication Engineering, Manipal Institute of Technology, Manipal Academy of \\ Higher Education, Manipal, India \\ ${ }^{5}$ Department of Mechatronics Engineering, Manipal Institute of Technology, Manipal Academy of Higher Education, \\ Manipal, India
}

\begin{tabular}{|c|c|}
\hline Article Info & ABSTRACT \\
\hline Article history: & This article introduces a planar monopole patch antenna for global \\
\hline Received Feb 7, 2020 & positioning system (GPS) application. Our design has a circular patch with \\
\hline Revised Apr 3, 2020 & ground. Our proposed design of the stub allows the antenna to operate \\
\hline Accepted May 4, 2020 & $\begin{array}{l}\text { at a frequency of } 1.5 \mathrm{GHz} \text {. The circular monopole is fed by an offset feeding } \\
\text { to have an impedance match of } 50 \mathrm{ohms} \text {. The compact antenna has been }\end{array}$ \\
\hline Keywords: & $\begin{array}{l}\text { designed and simulated on RT Duroid } 6006 \text { material with relative } \\
\text { permittivity }\left(\varepsilon_{r}\right) \text { of } 6.15 \text { and } 0.0019 \text { as the loss tangent. Our antenna has }\end{array}$ \\
\hline Circular monopole & a dimension of $65 \times 55 \times 2.54 \mathrm{~mm}^{3}$. A gain of $1.23 \mathrm{~dB}$ is observed at \\
\hline GPS & $\begin{array}{l}\text { the resonant frequency of } 1.5 \mathrm{GHz} \text { and the antenna exhibits dipole like } \\
\text { radiation pattern both in } \mathrm{E} \text { and } \mathrm{H} \text {-plane. The antenna has better impedance }\end{array}$ \\
\hline Inverted L-stub & matching, good gain and steady characteristics of radiation pattern across \\
\hline Offset feed & $\begin{array}{l}\text { the operating bandwidth. High frequency structure simulator (HFSS) v.13.0 } \\
\text { is used to carry out all the simulations. }\end{array}$ \\
\hline
\end{tabular}

This is an open access article under the $\underline{C C B Y-S A}$ license.

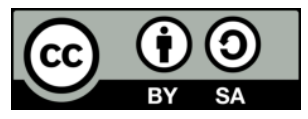

\section{Corresponding Author:}

Tanweer Ali,

Department of Electronics \& Communication Engineering,

Manipal Institute of Technology,

Manipal Academy of Higher Education, Manipal, India.

Email: tanweer.ali@manipal.edu

\section{INTRODUCTION}

Increasing numbers of researchers have used recent developments to build antennas that exhibit an increased gain, good efficiency, and are small in size with omnidirectional radiation patterns since the time wireless communication began to make major advances and began to gain popularity in everyday applications. Monopole antennas have become one of the worldwide elements of cellular and Internet networks. They are made a clear choice for developing countries by their relatively low cost and rapid implementation. The feature of the operation of these antennas in multiple bands to catering to the services of wireless local area network (WLAN), Wireless Interoperability for microwave access (WiMAX) and ultrawideband (UWB), motivates researchers in designing antennas that are compact and have triple or quad-band characteristics. The creation of slots in different positions results in varied radiation patterns and designs of novel antennas.

Literature reports numerou antennas in this regard. Ali et al. [1] have proposed a slot antenna for UWB applications. Ali [2] et al. have described the design of a slot reconfigurable fractal antenna in the shape of 'Koch' for WLAN/WiMAX operations. A truncated ground plane UWB antenna has been 
proposed by Saadh AW et al. [3] for GPS/Wi-Fi operation. A slot antenna has been created and tested by J. Dong et al. [4] for applications of mobile devices. Ali et al. [5] have presented a rectangular slot antenna with modified ground plane to work for UWB range thereby covering WLAN/WiMAX/MIMO applications. C. Rajagopal et al. [6] have presented a circular patch antenna with a T-shaped slot which can be used for multiple input multiple output (MIMO) applications.

The design of planar inverted F antenna (PIFA) antennas has been explored for various wireless applications by several researchers. M. Agarwal et al. [7] and A. M. Soliman et al. [8] have presented their designs of PIFAs for GPS and USB applications respectively. Fractal antennas have also been explored in literature for the design of various antennas for wireless applications. A trapezoidal shaped ring has been designed by V. Rajesh Kumar et. al [9]. S. Sivasundarapandian [10] has explored the domain of the UWB antenna design for cognitive radio by designing a Koch snowflake planar antenna. Yet another Sierpinsiki antenna has been designed and experimented for wireless applications by M. Ram et al [11].

The structural configuration of a defected ground plane has been explored in the following literature. A. Kunwar et al. [12] have designed an inverted L-slot antenna for WLAN and/ or WiMAX bands with a defected ground structure. J. Pei et al. [13] have designed a miniature antenna with a defected ground plane for UWB applications of WLAN and WiMAX.

Apart for this, monopole antennas of varied shapes such as inverted-L (Y. Xu et al. [14] and H. Chen et al. [15]), C-shaped strip (Li Kang et al. [16]), E-shaped radiator (M. A. Honarvar et al. [17]), bended strips (L. Wu et al. [18], K. Mondal et al. [19]), flower-shaped (S. Ullah et al. [20]), inverted G-shaped (W. Zaman et al. [21]), H-shaped (T. H. Chang [22]); have been explored and experimented for various wireless applications.

In this paper, a monopole antenna with a circular shape loaded with inverted L-shaped stubs with offset feeding is proposed. The antenna has a partial ground plane which helps in overall impedance matching at $1.5 \mathrm{GHz}$. The presented paper has the following main contributions:

- A compact circular monopole loaded with inverted L-shaped stubs with offset feeding is proposed for $1.5 \mathrm{GHz}$ band thus, satisfying the need of GPS applications.

- $\quad$ The inverted L-shaped stub helps in shifting the resonance from 2.1 to $1.5 \mathrm{GHz}$. This stub primarily helps in achieving compactness and resonance at $1.5 \mathrm{GHz}$ by changing the total surface current path length.

- $\quad$ The offset feeding and partial ground plane help in achieving better impedance matching performances thereby eliminating the requirement of external matching circuits.

- The main merit of the design is its compact size, planar structure, acceptable gain and simple configuration which make it very efficient to be integrated with various portable wireless handheld devices.

The next section of this article describes the design approach. Section III of this article presents the study of parameters related to the proposed design. Section IV of the article presents the results achieved and the discussion. Section $\mathrm{V}$ concludes the article.

\section{ANTENNA DESIGN METHODOLOGY}

The proposed antenna is designed using HFSS v13.0 software. Initially, the antenna is designed using a circular patch with symmetrical feed line and full ground plane. It is termed as antenna L represented in Figure 1(a). Here antenna does not operate at any frequency. $S_{11}$ defines the reflection coefficient and its $\mathrm{dB}$ value reaches zero indicates that nearly all power fed is flowing back towards feed. So, the value must be negative as small as less than $-10 \mathrm{~dB}$. The characteristic of antenna $\mathrm{L}$ tells that it does not match this requirement at $1.5 \mathrm{GHz}$ band as illustrated in Figure 1(b).

In the next stage, the antenna is modified with asymmetrical (offset) feed line and termed as antenna $M$ represented in Figure 1(a). In this stage also, the antenna does not operate at any band as depicted in Figure 1(b). For the next stage, the ground plane is etched into the partial ground according to a particular dimension. This antenna is named antenna $\mathrm{N}$ and represented in Figure 1 (a). Here, the antenna operates at $2.5 \mathrm{GHz}$ with maximum $\mathrm{S}_{11}=-25 \mathrm{~dB}$. To implement monopole, a partial ground plane is used as illustrated in Figure 1(b).

To shift the resonance from $2.5 \mathrm{GHz}$ as obtained by antenna $\mathrm{N}$ to $1.5 \mathrm{GHz}$, in the next stage a vertical stub is introduced to circular monopole design. This antenna is referred as antenna $\mathrm{O}$ and is represented in Figure 1(a). At this stage, antenna operates at $2.1 \mathrm{GHz}$ with maximum $\mathrm{S}_{11}=-35 \mathrm{~dB}$ as shown in Figure 1(b). As the antenna is almost near to the desired result, to tune this, a horizontal stub is introduced in the proposed antenna. Thus, the combination of these two stubs laid to the formation of stubs of inverted L-shape as illustrated in antenna $\mathrm{P}$ of Figure 1(a). Thus, antenna $\mathrm{P}$ forms the proposed design wherein it is seen that the antenna radiates at $1.5 \mathrm{GHz}$ with maximum $\mathrm{S}_{11}=-28 \mathrm{~dB}$. Thus, the introduction of 
L-shaped inverted stubs affects the surface current distribution which causes an intervention to the total current length path, as a result, causing the antenna to exhibit the band at $1.5 \mathrm{GHz}$. The variation of the reflection coefficient with respect to the antenna L, M, N, O and P is shown in Figure 1(b).

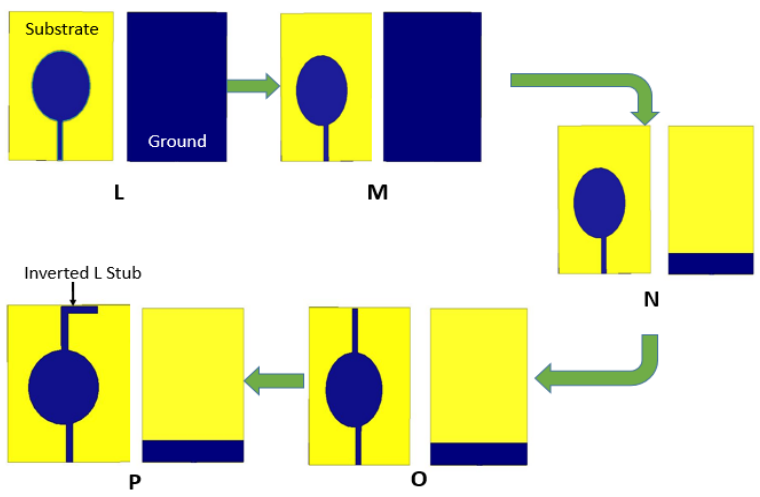

(a)

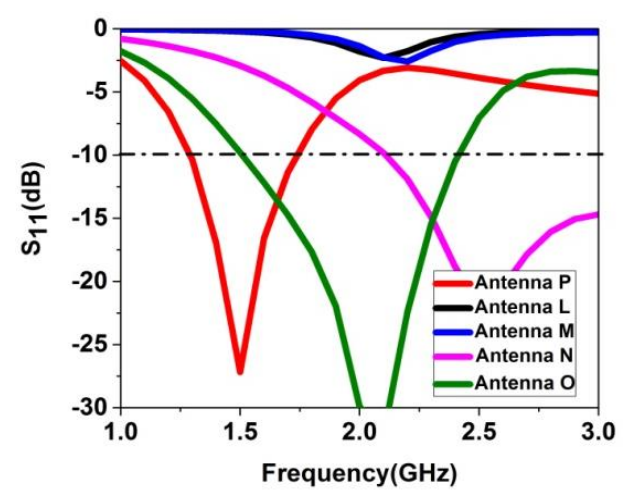

(b)

Figure 1. Proposed configuration, (a) Steps of design process, (b) $S_{11}$ results of design process

The detailed layout of the antenna is depicted in Figure 2. The antenna has a partial ground plane with ground plane width $\mathrm{Gw}$, circular monopole with diameter $\mathrm{C}_{\mathrm{D}}$ and inverted L-shaped stub, with horizontal length $\mathrm{R}_{\mathrm{L}}$ and width $\mathrm{R}_{\mathrm{W}}$, and vertical length $\mathrm{S}_{\mathrm{L}}$ and width $\mathrm{S}_{\mathrm{W}}$. The resonance at $1.5 \mathrm{GHz}$ is achieved by offset feed line and inverted L-shaped stub. The positioning of each structure (i.e. circular patch, offset feed line and inverted L-shaped stub) controls a given operating band. The antenna has dimensions of $65 \times 55 \times 2.54 \mathrm{~mm}^{3}$ and the substrate material (with Length $\mathrm{Y}_{\mathrm{L}}$ and width $\mathrm{Y}_{\mathrm{W}}$ ) used is Rogers RT duroid $6006(\mathrm{tm})$ with the dielectric constant of $6.15, \mathrm{~h}=2.54 \mathrm{~mm}$ and loss tangent $\delta=0.0019$. The proposed design detail dimensions are reflected in Table 1. The resonance frequency (i.e. 1.5 GHz) of the proposed GPS antenna can be calculated from (1).

$$
f_{r}=\frac{c}{4 \times Y_{L} \times 3.23 \times \sqrt{\varepsilon_{e f f}}}
$$

Where $c$ is the speed of light in free space, $Y_{L}$ is the maximum length of the antenna, $\varepsilon_{e f f}$ is the effective dielectric constant given by (2) and 3.23 is a multiplying constant.

$$
\left.\varepsilon_{\text {eff }}=\frac{\varepsilon_{r}+1}{2}+\frac{\varepsilon_{r}-1}{2}\left(1+12 \frac{h}{W}\right)\right)^{-0.5}
$$

On calculation, $Y_{L}=65, \varepsilon_{e f f}=5.64\left(\right.$ as $\left.\frac{W}{h}>1\right), c=3 \times 10^{8} \mathrm{~m} / \mathrm{sec}$, the resonace frequency comes around to be $1.5 \mathrm{GHz}$.

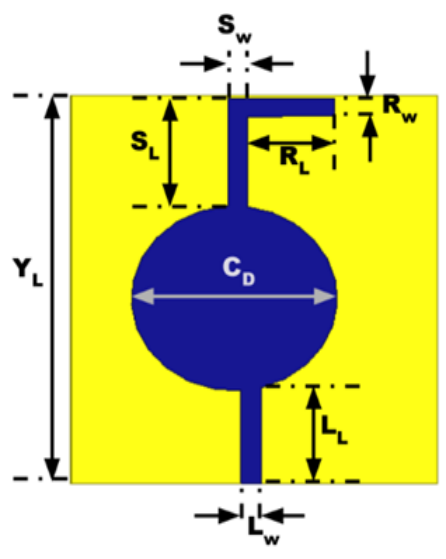

(a)

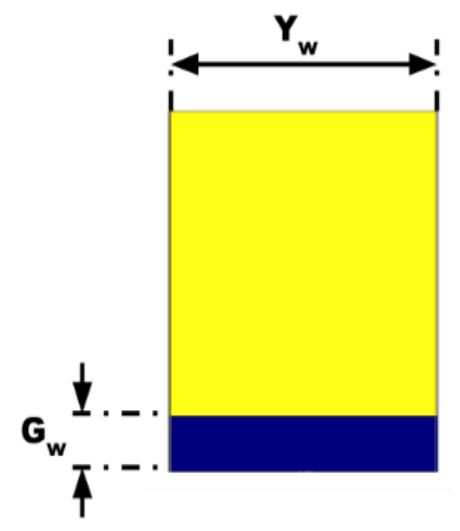

(b)
Table 1. Dimensional details of the proposed design

\begin{tabular}{cc}
\hline Parameters & Dimensions $(\mathrm{mm})$ \\
\hline $\mathrm{Y}_{\mathrm{L}}$ & 65 \\
$\mathrm{C}_{\mathrm{d}}$ & 31 \\
$\mathrm{LL}$ & 18.6 \\
$\mathrm{Sw}$ & 3 \\
$\mathrm{Rw}$ & 3 \\
$\mathrm{Yw}$ & 55 \\
$\mathrm{Gw}$ & 10 \\
$\mathrm{LW}$ & 3 \\
$\mathrm{SL}$ & 15.4 \\
$\mathrm{RL}$ & 13 \\
\hline
\end{tabular}

Figure 2. The layout of the proposed design, (a) Front, (b) Back 
The effect of the introduced stub on current density is illustrated in Figure 3. The current distribution at $1.5 \mathrm{GHz}$ is denser around the feed line and also at the inverted L-shaped stub. Thus, it provides better impedance matching at lower resonance.
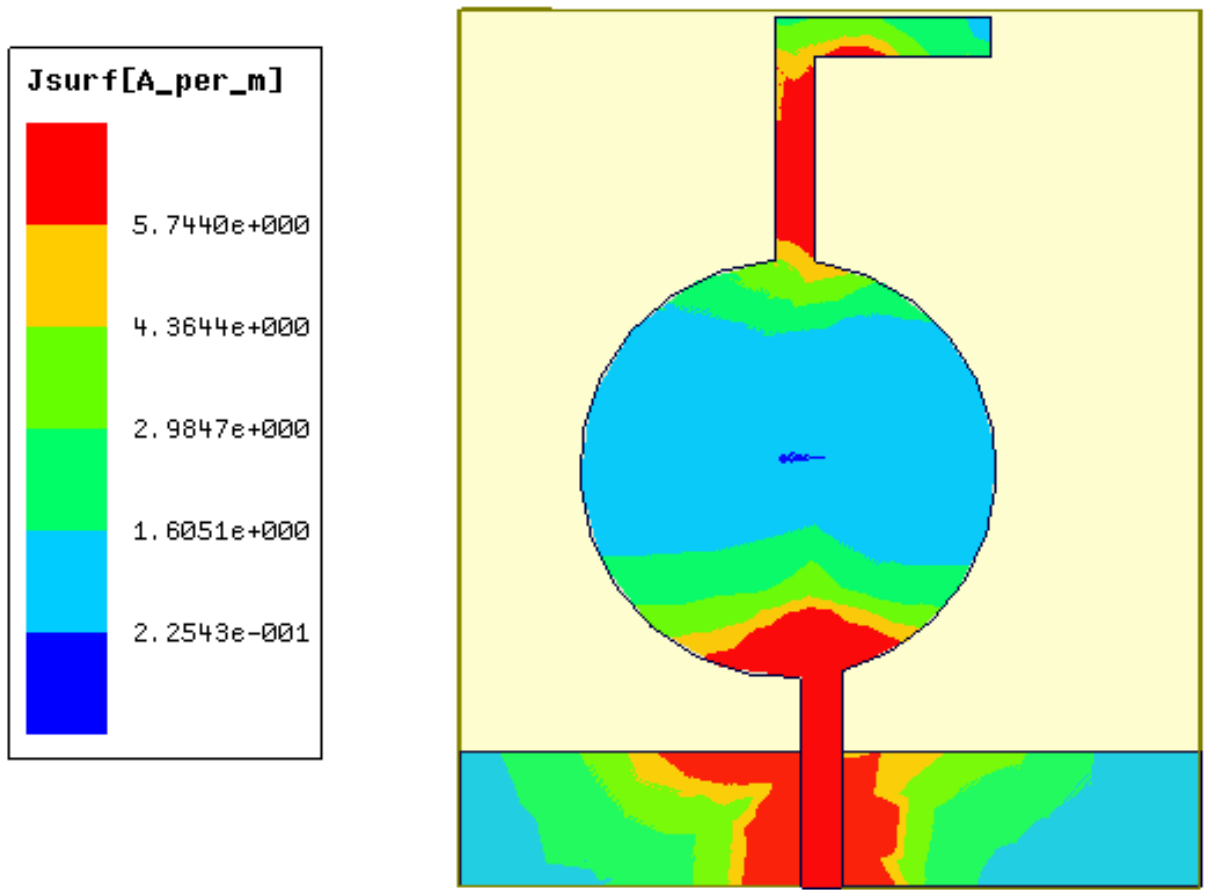

Figure 3. Current density at $1.5 \mathrm{GHz}$

\section{PARAMETRIC STUDY OF THE DESIGN}

To investigate the impact of the stub on the performance of the antenna, a parametric analysis is done. Since the performance of the design is influenced by the diameter of the circular patch, width of the ground plane, width of the vertical and horizontal stub. Hence, the study is completed for $\mathrm{Cd}, \mathrm{Gw}, \mathrm{Sw}$ and $\mathrm{Rw}$ respectively.

\subsection{Effect of circular patch $C_{d}$}

The effect of circular patch $\mathrm{Cd}$ on antenna impedance matching is observed. The study is completed by varying the diameter of the circular patch. The change of reflection coefficient with reference to $\mathrm{Cd}$ is as shown in Figure 4(a).

\subsection{Effect of $\boldsymbol{G}_{w}$}

The effect of the width of the ground plane is studied by varying the dimensions of $\mathrm{Gw}$ and keeping other dimensions constant. The desired result is obtained for $\mathrm{GW}=10 \mathrm{~mm}$ and is shown in Figure 4(b).

\subsection{Effect of $S_{w}$}

The effect of vertical stub width Sw on antenna impedance matching is observed. The study is done by varying the stub width $\mathrm{Sw}$ and keeping other dimensions constant. The change of the reflection coefficient with respect to $\mathrm{Sw}$ is shown in Figure 4(c).

\subsection{Effect of $\boldsymbol{R} \boldsymbol{w}$}

The effect of horizontal stub width Rw on antenna impedance matching is observed. The study is done by varying the stub width Rw and keeping other dimensions constant. The variance of the reflection coefficient with respect to Rw is shown in Figure 4(d). 


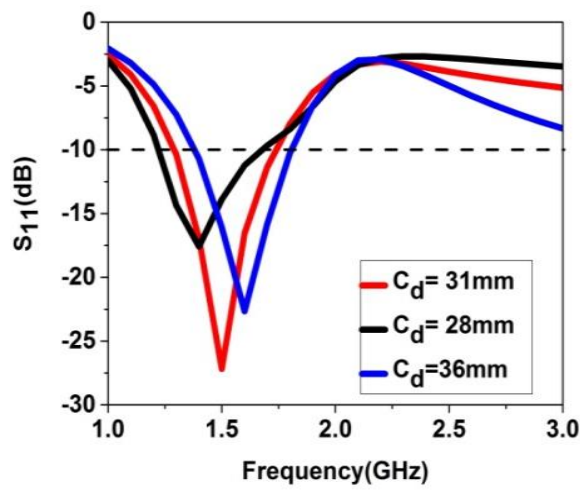

(a)

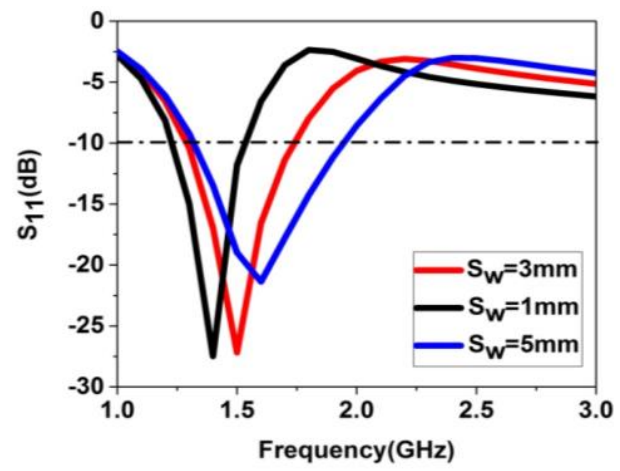

(c)

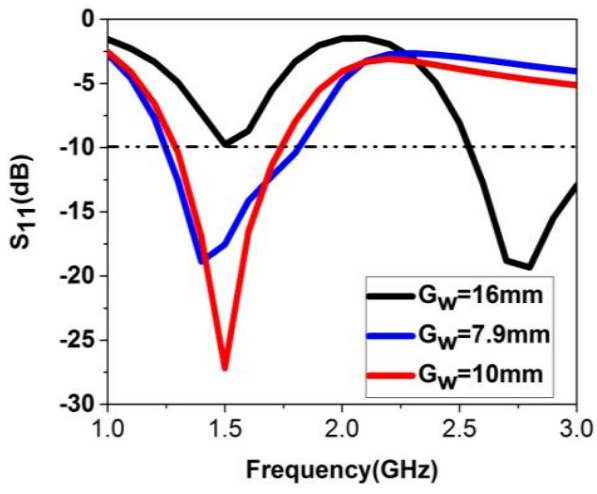

(b)

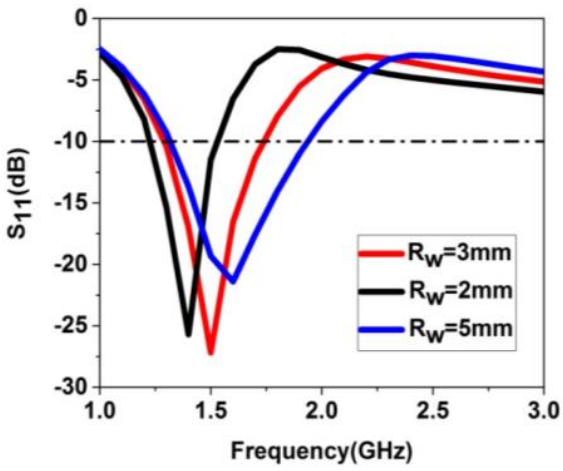

(d)

Figure 4. Study of parameters for (a) Cd, (b) Gw, (c) $\mathrm{Sw}$ and (d) $\mathrm{R}_{\mathrm{W}}$

\section{RESULTS AND DISCUSSION}

The simulation result for the proposed antenna is illustrated in Figure 5. The $\mathrm{S}_{11}<-10 \mathrm{~dB}$ impedance bandwidth for the simulation is about $33.3 \%(1.27-1.77 \mathrm{GHz})$. The obtained result and the optimized dimensions make it useful for GPS applications.

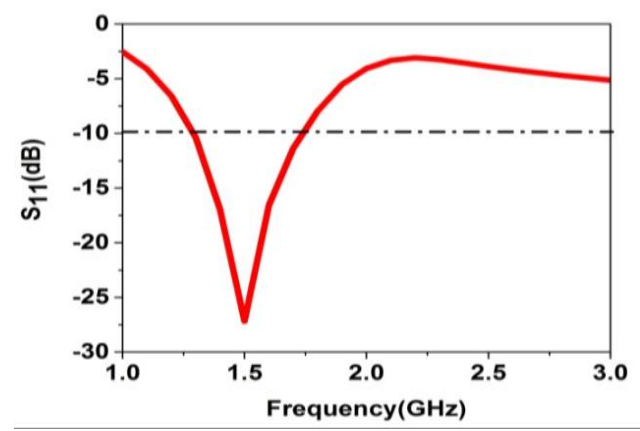

Figure 5. Reflection coefficient $\left(\mathrm{S}_{11}\right)$ of the designed antenna

\subsection{Total gain}

The total gain for the proposed antenna is illustrated in Figure 6. The antenna has a total gain of around $1.23 \mathrm{~dB}$ at $1.5 \mathrm{GHz}$ which is the operating frequency. Also, the gain plot gives information about the $3 \mathrm{D}$ radiation pattern. 


\subsection{Radiation pattern}

The radiation pattern of the designed antenna in $2 \mathrm{D}$ is illustrated in Figure 7 . The antenna has a figure-of-eight pattern in E-plane and zero like pattern in H-plane. A comparison is drawn between our antenna and its similar types which are illustrated in Table 2. It can be observed that our design has the advantage of better gain and size over its counterparts.

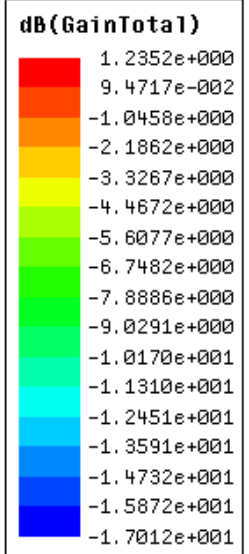

Figure 6. Total gain of the designed antenna

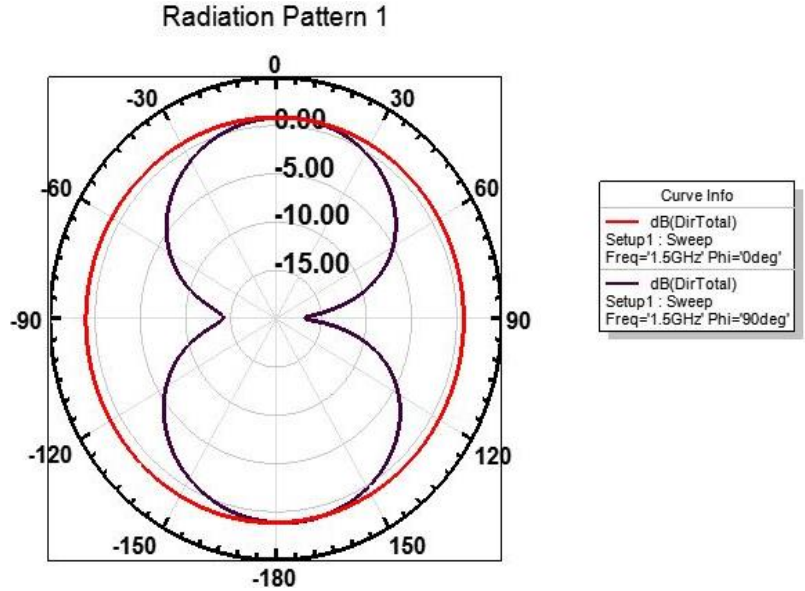

Figure 7. The radiation pattern of the proposed antenna (red line: -H-plane, black line: -E-plane)

Table 2. Comparative Analysis of the proposed antenna and antennas in the existing literature

\begin{tabular}{ccccc}
\hline Reference & $\begin{array}{c}\text { Size } \\
\left(\mathrm{mm}^{2}\right)\end{array}$ & Bandwidth & $\begin{array}{c}\text { Gain } \\
(\mathrm{dB})\end{array}$ & Application \\
\hline$[23]$ & $115 \times 42$ & $376 \mathrm{MHz}$ & 0.8 & GSM \\
{$[24]$} & $115 \times 60$ & $271 \mathrm{MHz}$ & 2.5 & GSM, WLAN \\
{$[25]$} & $70 \times 50$ & $206 \mathrm{MHz}$ & - & WiMAX \\
{$[26]$} & $44 \times 56$ & $90 \mathrm{MHz}$ & -2 & GPS \\
{$[27]$} & $88 \times 88$ & $40 \mathrm{MHz}$ & -0.7 & GSM \\
{$[28]$} & $140 \times 75$ & $262 \mathrm{MHz}$ & - & LTE \\
Our design & $65 \times 55$ & $500 \mathrm{MHz}$ & 1.23 & GPS \\
\hline
\end{tabular}

\section{CONCLUSION}

In the discussed paper a circular monopole antenna with an inverted L-shape for GPS application is proposed. The antenna utilizes offset feeding and partial ground plane to attain good impedance matching for the criteria $S_{11}<-10 \mathrm{~dB}$. Antenna demonstrates a dipole like pattern and also attains an acceptable value of gain for the desired band. From the parametric investigation, it is noted that by varying the value of optimized dimensions there is a considerable consequence on the antenna's impedance matching. Better impedance matching, good gain and steady radiation performances make the proposed configuration suitable for GPS applications.

\section{REFERENCES}

[1] Tanweer Ali, B. K. Subhash, Sameena Pathan, Rajashekhar C. Biradar, "A compact decagonal-shaped UWB monopole planar antenna with truncated ground plane," Microwave and Optical Technology Letters, vol. 60, no. 12, pp. 2937-2944, 2018.

[2] Tanweer Alia, Nikhat Fatimab, Rajashekhar C. Biradar, "A miniaturized multiband reconfigurable fractal slot antenna for GPS/GNSS/Bluetooth/WiMAX/X-band applications," AEU-International Journal of Electronics and Communications, vol. 94, pp. 234-243, 2018.

[3] S. A. W. Mohammad, M. M. Khaleeq, T. Ali and R. C. Biradar, "A miniaturized truncated ground plane concentric ring shaped UWB antenna for wireless applications," 2017 2nd IEEE International Conference on Recent Trends in Electronics, Information \& Communication Technology (RTEICT), Bangalore, pp. 116-120, 2017.

[4] Jian Dong, Xiaping Yu, and Guoqiang Hu, "Design of a compact quad-band slot antenna for integrated mobile devices," International Journal of Antennas and Propagation, 2016.

[5] Tanweer Ali, Mohammad Saadh A. W., Rajashekhar C. Biradar, Aurora Andújar, Jaume Anguera, "A miniaturized slotted ground structure UWB antenna for multiband applications," Microwave and Optical Technology Letters, vol. 60 , no. 8, pp. 2060-2068, 2018. 
[6] Chithradevi Rajagopal, Sreeja Balakrishnapillai Suseela, Nafiza Noorullakhan, Radha Sankararajan, "Compact modified 'T'slot circular patch quad band antenna for MIMO applications," International Journal of Microwave and Wireless Technologies, vol. 9, no. 4, pp. 865-873, 2017.

[7] M. Agarwal, R. Singh and M. K. Meshram, "Linearly polarised planar inverted F-antenna for global positioning system and worldwide interoperability for microwave access applications," in IET Microwaves, Antennas \& Propagation, vol. 7, no. 12, pp. 991-998, 17 Sept. 2013

[8] A. M. Soliman et al., "Inspired metamaterial quad-band printed inverted-F (IFA) antenna for USB applications," Applied Computational Electromagnetics Society Journal, vol. 30, no. 5, pp. 564-570, 2015.

[9] V. Rajeshkumar and S. Raghhavan, "Trapezoidal ring quad-band fractal antenna for WLAN/WiMAX applications," Microwave and Optical Technology Letters, vol. 56, no. 11, pp. 2545-2548, 2014.

[10] S. Sivasundarapandian and C. D. Suriyakala, "A planar multiband Koch snowflake fractal antenna for cognitive radio," International Journal of Microwave Wireless Technology, vol. 9, no. 2, pp. 335-339, 2017.

[11] M. Ram, S. Das and R. L. Yadava, "A quad band Sierpinski trapezoidal fractal patch antenna for wireless applications," Journal of Microwaves, Optoelectronics \& Electromagnetic Applications, vol. 16, no. 1, pp. $25-37,2017$.

[12] Alaknanda Kunwar et al., "Inverted L-slot triple-band antenna with defected ground structure for WLAN and WiMAX applications," International Journal of Microwave Wireless Technology, vol. 9, no. 1, pp. 191-196, 2017.

[13] J. Pei, A. Wang, S. Gao and W. Leng, "Miniaturized triple-band antenna with a defected ground plane for WLAN/WiMAX applications," in IEEE Antennas and Wireless Propagation Letters, vol. 10, pp. 298-301, 2011.

[14] Y. Xu, C. Zhang, Y. Yin and Z. Yang, "Compact triple-band monopole antenna with inverted-L slots and SRR for WLAN/WiMAX applications," Progress in Electromagnetic Resonance Letters, vol. 55, pp. 1-6, 2015.

[15] H. Chen, X. Yang, Y. -.Yin, J. -. Wu and Y. -. Cai, "Tri-band rectangle-loaded monopole antenna with inverted-1 slot for WLAN/WiMAX applications," in Electronics Letters, vol. 49, no. 20, pp. 1261-1262, 26 September 2013

[16] L. Kang, X. H. Wang, H. Li and X. W. Shi, "Planar monopole antenna with a compact radiator for tri-band applications," Microwave Optical Technology Letters, vol. 57, no. 3, pp. 706-709, 2015.

[17] M. A. Honarvar, N. Hamidi and B. S. Virdee, "Multiband antenna for portable device applications," Microwave Optical Technology Letters, vol. 57, no. 4, pp. 956-959, 2015.

[18] Lierong Wu, Jingjian Huang and Naichang Yuan, "Compact multiband monopole antenna for GPS/WLAN/WiMAX application," 2016 IEEE International Conference on Microwave and Millimeter Wave Technology (ICMMT), Beijing, pp. 618-620, 2016.

[19] K. Mondal, A. Samanta and P. P. Sarkar, "Compact multiband monopole antenna for ISM band $2.4 \mathrm{GHz}$, Bluetooth, WiMAX, Wi-Fi applications,” Wireless Personal Communications, vol. 97, no. 1, pp. 181-195, 2017.

[20] Sadiq Ullah, Farooq Faisal, Ashfaq Ahmad, Usman Ali, Farooq Ahmad Tahir, James A. Flint, "Design and analysis of a novel tri-band flower-shaped planar antenna for GPS and WiMAX applications," Journal of Electromagnetic Waves Applications, vol. 31, no. 9, pp. 927-940, 2017.

[21] W. Zaman, H. Ahmad and H. Mehmood, "A miniaturized meandered printed monopole antenna for triband applications," Microwave Optical Technology Letters, vol. 60, no. 5, pp. 1265-1271, 2018.

[22] T. Chang and J. Kiang, "Compact multi-band H-shaped slot antenna," in IEEE Transactions on Antennas and Propagation, vol. 61, no. 8, pp. 4345-4349, Aug. 2013.

[23] T. Zhang, R. Li, G. Jin, G. Wei and M. M. Tentzeris, "A Novel Multiband Planar Antenna for GSM/UMTS/LTE/Zigbee/RFID Mobile Devices," in IEEE Transactions on Antennas and Propagation, vol. 59, no. 11, pp. 4209-4214, Nov. 2011.

[24] H. Liu, R. Li, Y. Pan, X. Quan, L. Yang and L. Zheng, "A multi-broadband planar antenna for GSM/ UMTS/LTE and WLAN/WiMAX handsets," in IEEE Transactions on Antennas and Propagation, vol. 62, no. 5, pp. 2856-2860, May 2014.

[25] A. T. Abed and M. S. J. Singh, "Slot antenna single layer fed by step impedance strip line for Wi-Fi and Wi-Max applications," in Electronics Letters, vol. 52, no. 14, pp. 1196-1198, 772016

[26] Y. F. Cao, S. W. Cheung and T. I. Yuk, "A multiband slot antenna for GPS/WiMAX/WLAN systems," in IEEE Transactions on Antennas and Propagation, vol. 63, no. 3, pp. 952-958, March 2015.

[27] N. Nguyen-Trong, A. Piotrowski and C. Fumeaux, "A frequency-reconfigurable dual-band low-profile monopolar antenna," in IEEE Transactions on Antennas and Propagation, vol. 65, no. 7, pp. 3336-3343, July 2017.

[28] H. Chen, H. Yang and C. Sim, "Single open-slot antenna for LTE/WWAN smartphone application," in IEEE Transactions on Antennas and Propagation, vol. 65, no. 8, pp. 4278-4282, Aug. 2017.

\section{BIOGRAPHIES OF AUTHORS}

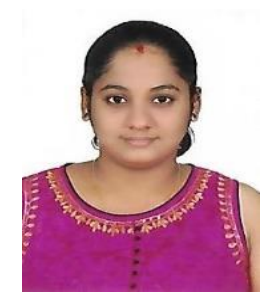

Sowmya G. A. was born in Udupi, Karnataka, India. In 2016, she obtained her Bachelor of Engineering degree (BE) in Electronics and Communication Engineering from Srinivas Institute of Technology, Mangalore, Karnataka. She is currently pursuing her M. Tech in Digital Electronics and Communication from Manipal Institute of Technology (2019-2021), Manipal, Karnataka, India. Her research area is communication and antenna design. 

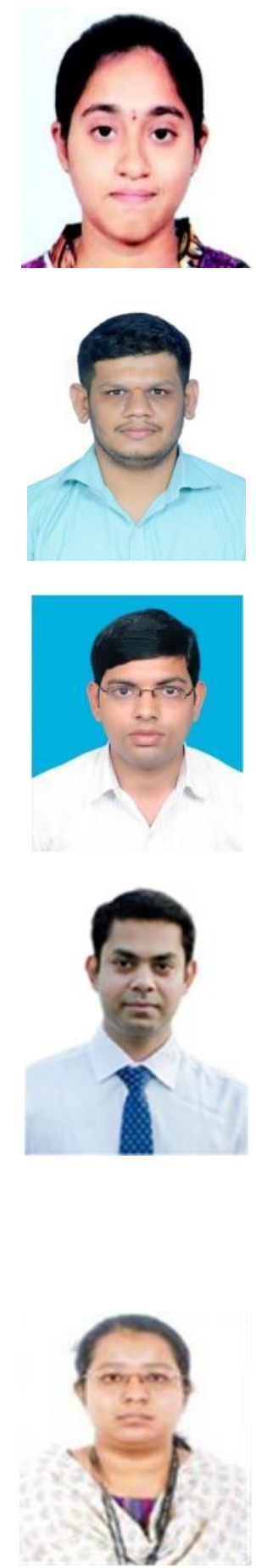

Akshatha Kamath was born in Mangalore, Karnataka, India. In 2019, she obtained her Bachelor of Engineering degree (BE) in Electronics and Communication Engineering from Bharat Institute of Technology, Ibrahimpatnam, Telangana. She is currently pursuing her M. Tech in Digital Electronics and Communication from Manipal Institute of Technology (20192021), Manipal, Karnataka, India. Her research area is communication and VLSI.

Anala Keshava was born in Bantwal, Dakshina Kannada, Karnataka, India. In 2019, he obtained his Bachelor of Engineering degree (BE) in Electronics and Communication Engineering from Canara Engineering College, Benjanapadavu, Mangalore. He is currently pursuing his M. Tech in Digital Electronics and Communication from Manipal Institute of Technology (2019-2021), Manipal, Karnataka, India. His research area is communication and Antenna Design.

Om Prakash Kumar is an Assistant Professor in the Dept. of Electronics \& Communication Engineering at Manipal Institute of Technology, Manipal Academy of Higher Education, Manipal. He has authored more than 20 research articles in high impact factor SCI journals. His research field includes UWB Antennas, Multiband antennas and metamaterial antennas.

Tanweer Ali is working as Assistant Professor in the Department of Electronics \& Communication Engineering at Manipal Instituteof Technology, Manipal Academy of Higher Education, Manipal. He is an active researcher in the field of microstrip antennas, wireless communication and microwave Imaging. He has published more than 65 papers in reputed peer reviewed international journal and conferences. He is a senior member IEEE (SMIEEE), and Associate Member of IETE India. He is on the board of reviewers of journals like the IEEE Transactions on Antennas and Propagation, IEEE Antennas and Wireless Propagation Letters, IET Microwaves, Antennas \& Propagation, IET Electronics letter, Wireless Personal Communication (WPC), Springer, AEU-International Journal of Electronics and Communications, Microwave and optical Technology letters (MOTL), Wiley, International Journal of Antennas and Propagation, Hindawi., Advanced Electromagnetics, Progress in Electromagnetic Research (PIER), KSII Transaction ofEngineering Science, Korea, International Journal of Microwave andWireless Technologies, Frequenz, Radio engineering etc.

Shweta Vincent is an Assistant Professor in the Dept. of Mechatronics Engineering at Manipal Institute of Technology, Manipal Academy of Higher Education, Manipal. Her research field includes UWB Antennas, Multiband antennas and metamaterial antennas. 